\title{
Preterm Premature Rupture of Membrane
}

National Cancer Institute

\section{Source}

National Cancer Institute. Preterm Premature Rupture of Membrane. NCI Thesaurus. Code C92862.

Spontaneous rupture of fetal membranes that occurs before the onset of labor and before 37 weeks. 